\title{
First field records of the sexuales (males and oviparae) of Toxoptera aurantii (Hemiptera: Aphididae)
}

\author{
NICOLÁS PÉREZ HIDALGO' $\&$ DAVID MIFSUD ${ }^{2}$ \\ ${ }^{1}$ Departamento de Biodiversidad y Gestión Ambiental, Universidad de León, 24071 León, Spain. E-mail: nperh@unileon.es \\ ${ }^{2}$ University of Malta, Junior College, Department of Biology, Msida MSD 1252, Malta.E-mail: david.a.mifsud@um.edu.mt
}

Toxoptera aurantii (Boyer de Fonscolombe) is an aphid pest of great agricultural importance, not only due to its polyphagy but mostly due to its ability to transmit various plant viruses e.g. Citrus tristeza virus on Citrus (Blackman \& Eastop, 2000). Blackman \& Eastop (2000) considered this aphid to be entirely anholocyclic, because no sexual morphs have ever been observed in the field.

However, two alate males collected on Citrus in Palestine, December 1935 (15.xii.-letter dated) (F.S. Bodenheimer), are present in the collections at The Natural History Museum, London (Blackman \& Eastop, 2010), and more recently the first oviparous female was collected from the field in an aphid sample collected on Sambucus nigra in Malta (Valletta, Floriana Argotti Garden) on 4.xii.2008 (leg. A. Tabone). The oviparous female is deposited in the aphidological collection of the University of León, Spain (sample Malta-707).

The alate males collected in Palestine and the oviparous female collected in Malta present the clear diagnostic characters of the genus Toxoptera (presence of stridulatory apparatus consisting of lateroventral ridges [Fig. 1C] on the abdomen, and peg-like hairs on the hind tibiae), and of the species Toxoptera aurantii (black-and-white banded antennae [Figs. 1B, 2A] and fore wing with black pterostigma and median vein with two branches [Fig. 2C]).

The studied female is similar to viviparous females, but has the characters typical of oviparae: presence of eggs in abdomen (Fig. 1A), thick hind tibiae, with about 170 pseudosensoria (Fig. 1A, E), and cauda and genital plate (Fig. 1D) with more setae (19 and 59, respectively) than viviparous females. In addition the body length is $1.97 \mathrm{~mm}$, the antennal segments I-VI measure $0.085,0.07,0.33,0.26,0.25$ and $0.09+0.44 \mathrm{~mm}$, the rostrum is $0.43 \mathrm{~mm}$, and its apical segment is $0.11 \mathrm{~mm}$ and has two complementary setae (they measure $0.057 \mathrm{~mm}$ ), the cauda is $0.20 \mathrm{~mm}$, and the siphunculi are $0.21 \mathrm{~mm}$. The setae of abdominal segment III are around $0.025 \mathrm{~mm}$, and the setae on antennal segment III are $0.025 \mathrm{~mm}$ (about 0.71 times the base of the segment).

The studied males (Fig. 2B) are also similar to viviparous females, with black pterostigma and median vein with two branches (Fig. 2C), but they have typical male characters: well sclerotized genital structure (Fig. 2D), abdomen more slender and small, more numerous rhinaria on antennal segments (34-44, 23-29, and 10-18 on antennal segments III-V respectively), and shorter siphunculi and cauda (Fig. 2B). In addition the body length is $1.72-1.95 \mathrm{~mm}$, the antennal segments III-VI measure $0.33-0.38,0.31-0.32,0.26-0.27,0.08-0.11$ and $0.44-0.46 \mathrm{~mm}$, the rostrum is $0.49-0.56 \mathrm{~mm}$, and its apical segment is $0.11-0.12 \mathrm{~mm}$ and have two complementary setae, the cauda is $0.11-0.13 \mathrm{~mm}$ and have 8 and 10 setae, and the siphunculi are $0.17-0.18 \mathrm{~mm}$. The setae of abdominal segment III are $0.025-0.030 \mathrm{~mm}$ and the setae on antennal segment III are $0.020-0.022 \mathrm{~mm}$ (around 1.10-1.18 times the base of the segment).

The oviparous female found in Malta on Sambucus is quite an extraordinary event because since its original description, no oviparous females have ever been collected in the field. Moreover the presence of males in Palestine and the sexual female in Malta may also indicate that the Mediterranean area may have been the area of origin of this now almost cosmopolitan species.

\section{Acknowledgements}

We are grateful to Jon Martin for the loan of the slides of the male specimens of Toxoptera aurantii and to Roger L. Blackman and Victor F. Eastop for their critical comments to this present note. We also thank Sebastiano Barbagallo for all his assistance during the present work. The present work was elaborated in the context of the "Fauna Ibérica IX Project" (CGL2007-66786-C08-03). 


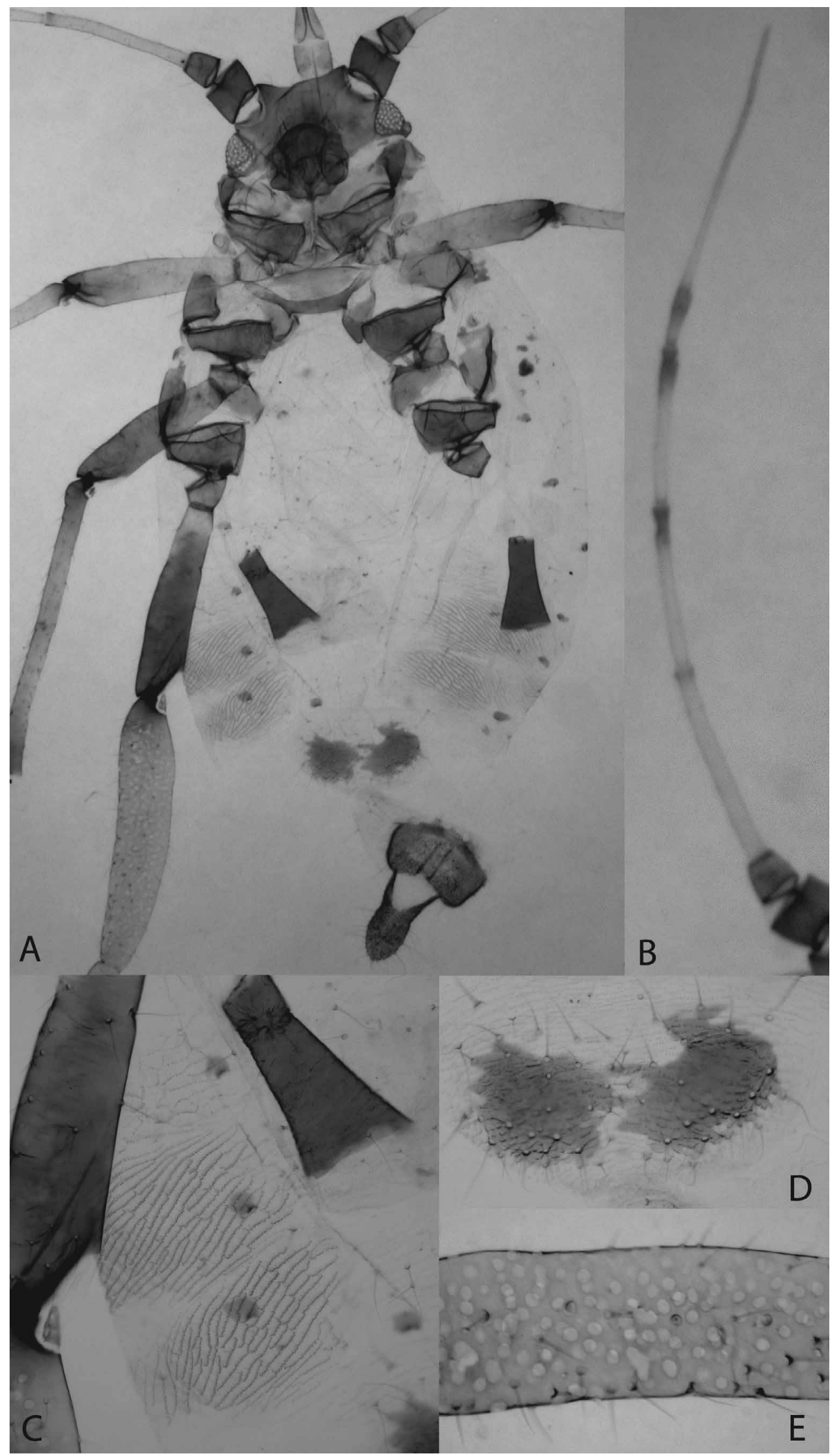

FIGURE 1. Toxoptera aurantii oviparous female: (A) body; (B) antennal segments III-V; (C) lateroventral ridges on abdomen; (D) genital plate; (E) detail of hind tibia with pseudosensoriae. 


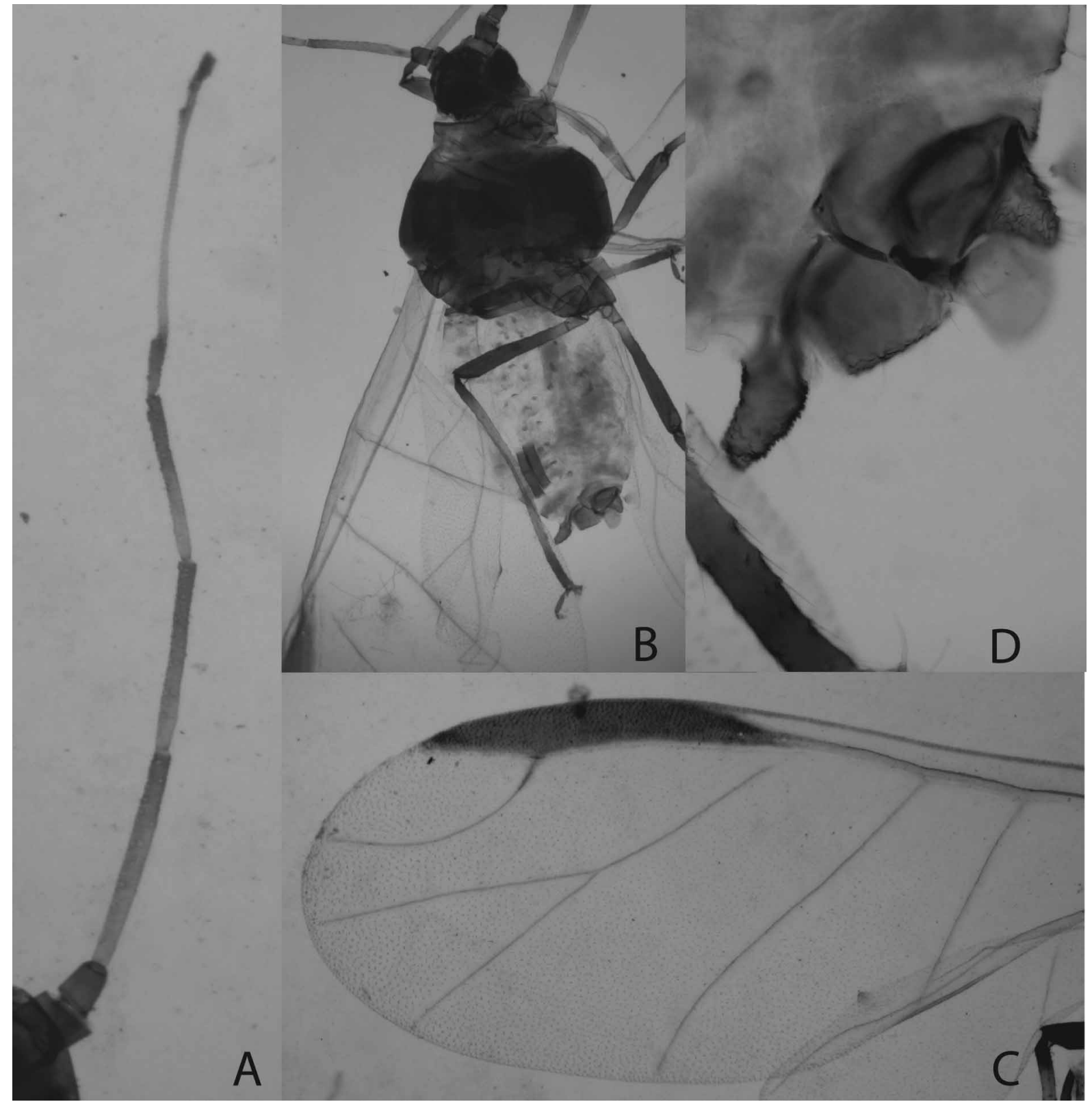

FIGURE 2. Toxoptera aurantii male: (A) antenna; (B) habitus; (C) fore wing; (D) detail of posterior abdomen.

\section{References}

Blackman, R.L. \& Eastop, V.F. (2000) Aphids on the World's Crops. An identification guide (second edition). J. Wiley \& Sons. Chichester. $8+466$ pp.

Blackman, R.L. \& Eastop, V.F. (2010) Aphids on the World's Trees. Available from: http:// www.aphidsonworldsplants.info/x_APHIDS_T.htm\#Toxoptera. (1-2-2011). 